\title{
Retraction Note: Applying TRIZ and AHP to develop innovative design for automated assembly systems
}

\section{Tesheng Li}

Published online: 22 November 2014

(C) Springer-Verlag London 2014

Retraction to: Int J Adv Manuf Technol (2010)

46(1-4):301-313

DOI 10.1007/s00170-009-2061-4

The article "Applying TRIZ and AHP to develop innovative design for automated assembly systems", published in International Journal of Advanced Manufacturing Technology, Volume 46, Issue 1-4, pp 301-313, DOI: 10.1007/s00170009-2061-4, has been retracted at the request of the Editorin-Chief because parts were simultaneously submitted to and published in Expert Systems with Applications, Volume 36, Issue 4, Pages 8302-8312, DOI: 10.1016/j.eswa.2008.10.025.

The online version of the original article can be found at http://dx.doi.org/ 10.1007/s00170-009-2061-4.

T. Li $(\triangle)$

Minghsin University of Science and Technology, Hsin Fong,

Hsinchu, Taiwan 304, Republic of China

e-mail: jeff@must.edu.tw 